\title{
An Institutional Perspective on the Challenges of Information Systems Innovation in Public Organisations
}

\author{
Gamel O. Wiredu \\ School of Technology, Ghana Institute of Management and Public Administration, \\ Accra, Ghana \\ gwiredu@gimpa.edu.gh
}

\begin{abstract}
Public organisations are normally overwhelmed with socio-technical challenges of Information Systems (IS) innovation at both organisational and institutional levels. However, most studies of these challenges adopt an organisational perspective, leaving the institutional perspective largely unanalysed. In this paper, the IS innovation challenges faced by a British local authority are analysed to explain the institutional roles of public bureaucracy and information technology (IT). The analysis reveals the tensions between the low-entrepreneurial ethos of public organisations and the efficiency principle of IT. The paper argues that the primary principle of IS innovation should be institutional adjustments of public bureaucracy and information technology. Suggestions on how both institutions can be adjusted are provided.
\end{abstract}

Keywords: Information systems innovation, public organisations, public bureaucracy, information management, e-government.

\section{Introduction}

Advances in information technology (IT) development have engendered pressing demands for public organisations to adopt them to consummate information systems (IS) innovation. IS innovation is defined as an organisation's application of IT to make its processes more efficient and effective [34, p.1072]. However, IS innovation in public organisations are confronted by challenges of IT integration [7], as witnessed in the high failure rate of government IT projects worldwide [13]. These challenges have recently engaged the attention of information systems (IS) and egovernment researchers. They have attempted to explain and address these challenges, but their models are limited for the following reasons.

Firstly, some researchers mainly focus on the relationship between the public organisation and the public, without much attention to the internal organisational processes [e.g. 11, 8, 18,6]. For this reason, information management as an important antecedent of the organisation's interface with the public is left unanalysed. Secondly, even if internal organisational processes are focused upon, researchers adopt overly situated perspectives that result in organisational- or micro-level analysis at the expense of institutional- or macro-level analysis [e.g. 20, 29, 4]. A few exceptions are Cordella [8], Henriksen and Damsgaard [19], and Fountain [14]. In so doing, the role 
of historical institutional antecedents are excluded in explanations of IT integration in public organisations. Thirdly, many approach IT integration with overly high degrees of IT optimism and determinism [e.g. 18, 13, 31, 24]. IT is so highly privileged that only organisational issues such as people, information, systems and change are problematised. Thus, apart from a few exceptions [e.g. 25], explanations of IT-related organisational change virtually leave the IT as a constant attribute. As a result of all these limitations, extant models preclude explanations of how the institutional relationship between IT and public bureaucracy shape information systems (IS) innovation in public organisations.

This paper, therefore, seeks to address these limitations by answering the question: how can the challenges of IS innovation in public organisations, presented by the interactions between IT and public bureaucracy, be explained and addressed? It takes an institutional approach to the analysis of organisational-level challenges of IS innovation. One aspect of this perspective is the consideration of IT as an institution in its own right [2]. Yet, the paper, at the same time, focuses on organisational processes. Through the analysis of the information management challenges faced by a British local government authority, it argues that the primary principle of IS innovation should be institutional adjustments of public bureaucracy and IT.

\section{Information Systems Innovation and Institutions}

Against the backdrop that innovation in an organisation refers to "the adoption of an idea or behaviour that is new to the organisation adopting it" [9, p.197], Swanson [34, p.1072] defines IS innovation as the application of IT to make processes more efficient and effective. But this definition suffers from the problem of IT determinism and optimism because it privileges IT as the unquestioned agent of IS innovation. Avgerou's [3] definition avoids this problem and presents a desirable framework for the analysis in this paper. She defines IS innovation as "IT innovation and organisational change, whereby both the IT items and the individual organisational actors involved are part of institutionalised entities, that are historically formed durable, but dynamic, heterogeneous networks" (p.64). She explains IS innovation by emphasising the interactions between the network of heterogeneous actors involved in the innovation. The heterogeneity in the network is represented by actors such as hardware, software, data, IT developers, vendors, users and consultants [cf. 26].

The mutual interrelations between this range of heterogeneous actors removes any presuppositions or accepted assumptions about the determining capacity of technology or society. Neither the social nor technical determines the other, signifying that socio-technical relationships can be understood in terms of the outer sociotechnical context of the network, including its institutional history. The outer sociotechnical context refers predominantly to the institutional fields of both IT and the bureaucracy, and also to politics.

The important role of the institutional context as a factor that bears on organisational interactions is a popular argument in institutional and organisational theory [e.g. 27, 10, 30]. An institutional structure is an order which is imbued with time-honoured values. These usually induce specific attitudes among employees in organisations. Furthermore, institutions are "social patterns that, when chronically reproduced, owe their survival to relatively self-activating social processes" [21, p.145]. Institutional structures bear on 
the details of what happens in organisational interactions - in the operational details which innovation is an instance.

Therefore, understanding the role of the institutional field of IT is important because IT is an institution in its own right $[2,3]$. The institutional essence of IT is summarily explained by Avgerou [2] in terms of the established value of technology for post-industrial society; an established array of professional experts devoted to innovating IT the established regulations for IT development and use; and powerful professional associations who promulgate standards of technology development and practice. IT is deemed as an institution because the momentum of its diffusion defies even negative analysis of its organisational value. Thus, IT is ubiquitous in almost all fields of endeavour where it is deemed to be enhancing productivity.

Just like IT, the institution of bureaucracy has acquired its own momentum and has its own norms of good practice in modern organisation. Thus, although post-modern thinkers of organisational governance tout bureaucracy as an institution that degrades human dignity and they celebrate its supposed demise, it remains the best alternative to the market. Both IT and bureaucracy are distinct institutions with their own orders. The foundations of the bureaucratic order are different from the foundations of the technological order, although the two orders interrelate in IS innovation.

\section{A Case of Information Management at Lambeth Borough Council}

The empirical component of this research, conducted in 2002, focused on Lambeth Borough Council (LBC) as the empirical case. LBC is the local government authority for London Borough of Lambeth (LBL). LBL is one of thirteen Boroughs of the Greater London area and occupies almost a central position in it. By the case study strategy [35], the study was aimed at understanding the IS innovation challenges in public organisations. The study investigated the Council's information management processes in the face of IT and public bureaucracy. The qualitative results, thus, highlight the dynamic behaviours of the main dependent elements of information management - people and information - in response to the institutions of IT and public bureaucracy. In operationalising this strategy, the data were collected through meetings, interviews, documents, the internet and the Council's intranet.

LBC's central aim of public services delivery presented immense challenges. It was in competition with other local councils in terms of Best Value Performance (BVP). BVP indicators had been formulated by the central government to provide a nationally consistent framework for measuring progress in public services delivery. The emergence of the Internet and World Wide Web imposed even greater challenges for BVP. Yet, at the time of this study, the council had not prepared a formal information and knowledge management strategy to guide its information-related decisions and operations. The state of information in the council corroborated a history of ad hoc information related decision-making in the council.

LBC was making efforts to accelerate the steps towards meeting these egovernment BVP targets, but only as far as providing information and consultation which were online, with the rest at the rudimentary stages of planning. Even with information provision, interviews indicated that searching for council documents online was frustrating. 
With over 10,000 documents scattered on its website, the council seemed to lack the appropriate search software to make online document search easy for its customers. Besides, metadata tagging of the documents was poor. The ability of the Council's website to support smooth documents search by the public was important with regard to accountability, information retrieval and retrieval times, and empowering the citizen with the information resource. Citizens' rights to access documents on the council's website had been given legal backing in the Freedom of Information (FoI) Act 2000. Thus, the council had a significant problem to tackle.

\section{Organisational Processes}

LBC's processes reflected personal and political power relations. The political processes thrived in unison and in various degrees of domination within the information handling processes. According to a member of the SMB,

"[There are] a mix of all of them! Actually, there needs to be another [process] random - because a lot of the time, decision-making processes have reflected crisis management and expedient solutions. But I would say that the political type is a generally true feature that permeates everything."

'Random' processes reflected in senior managers' attitude to IT. Although IT was embraced by them as a useful tool in the Council's operations especially egovernance, it was evident that IT had been isolated instead of being fully integrated into service delivery operations. As a result, a lot of middle managers were either circumspect or, at worst, doubtful about the prospects of IT.

"[Senior managers] see IT as an overhead. They have a long way to go to recognise the value and power of what is available on the desks of their staff. There are very few areas where process management and automation has been used to improve service delivery and/or cost." - Head of IT.

"We don't have good processes that we could easily automate. We still have lots of paper-based systems. The bulk of work is to make the processes work properly today before we can then automate." - a Councillor.

The council had planned to integrate information systems strategy with business strategy. There was sufficient evidence from the numerous BV Review reports and the council's objectives that pointed to attempts at alignment. Besides, its information systems were disintegrated and impliedly did not support collaboration of efforts from various divisions of the council.

"[There is] too much duplication, too little cohesiveness between departments" Head of IT.

"We had a history of managers spending their money as they wanted and they often did their own thing without thinking about what the person sitting next to them would be doing, and what the department next to them would be doing" - a Councillor.

\section{Information management and culture}

There did not seem to be any formalised mechanisms instituted to facilitate organisational learning at LBC.

"On organisational learning, my observation is very poor on things like learning from past strategic experience through controlled experiments and executive seminars. We are not really a data-driven organisation." - Director of Culture change. 
Organisational learning in the council was in this poor state because of its organisational culture. For instance, it was loosely assumed that every section of the council would play some minimum role towards effective and efficient use of information albeit unsystematic and disintegrated. The e-government and BV wind was blowing across the council, apparently because it was being enforced by the central government. But commitment levels were low among some managers and lower level employees, and the roles of various participants seemed disjointed. This was an immense challenge in terms of culture change. It was clear that the new ideology that was required to catalyze the change process within the council was not available, even at the management level.

"I think there is a real historical legacy here. Managers have had to make decisions without having [the required] information. Because there haven't been any information systems in place, they have usually made decisions based on inspiration, talking to few people, and often being quite successful in doing that." - Director of Culture Change.

Besides, fear of redundancy among lower-level staff was a significant factor that impacted negatively on commitment levels to changes in information handling within the council.

There was also a general lack of true understanding of what is achievable through the use of IT in the council. Even though many of the employees had a sense that computers and IT can do a lot of things, there were still many who were just not aware of how they could be used to enhance their activities. As a result, there was low use of IT in the council. It was observed that almost all desks had workstations.

"In terms of internal processes, I think as an organisation, we are not all good at using and sharing information. The fact that e-mail exists helps a lot but that mean that every manager is very heavily dependent on e-mail. We don't have shared drives, and we don't have bulletin board areas or anything like that." - member of SMB.

IT operations were intended to support business objectives. According to the Head of IT, although his department had specific objectives, there were no clearly defined strategies to ensure efficient and effective alignment of IT and business innovation.

\section{Public Organisations and Challenges of IS Innovation}

The case suggests that attempts at technology integration for information management are fraught with serious tensions between IT and public bureaucracy. The following analysis hinges on the integral components of information management - information and people. Each of these components is further analysed in terms of the institutions of IT and public bureaucracy to show the challenges facing IS innovation and how they can be addressed.

\subsection{Relationship between Public Bureaucracy and People}

Public bureaucracy as an institution had considerable effects on the employees of the Council and their activities. Public bureaucracies operate with a basic principle of equality and impartiality in their provision of services to citizens, thereby enforcing democratic values [8, p.270]. Grounded in this ethos, local councils operate as lowentrepreneurial bureaucracies $[32,28]$. This ethos is a context that affected the 
employees of the Council. For instance, their exhibition of random or ad hoc processes constituted enactments of political organisation. The employees' political decision-making processes that reflected crisis management and expedient solutions are reactive. According to Moe [28, p.127-127], the necessity for compromise in politics calls for expediency and effectiveness rather than efficiency in the design of public organisations. These processes exhibited by the employees of the Council also reflected their limited knowledge. Limited knowledge is usually caused by information barriers that prohibit information sharing and awareness creation between employees. Their paper-based information moved slowly, was difficult to access, and contributed to the creation of barriers to information. Political processes thrive in environments saturated with information barriers, but they leave employees destitute of shared knowledge.

\begin{tabular}{|c|c|c|c|}
\hline \multirow{2}{*}{ 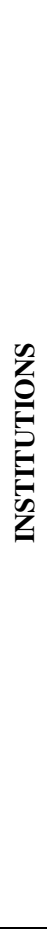 } & $\begin{array}{l}\text { Information } \\
\text { Technology }\end{array}$ & $\begin{array}{l}\text { Expected } \\
\text { - Nature (digital) } \\
\text { - Medium (computer) } \\
\text {-Knowledge (leaky) } \\
\text { - Movement (high speed) } \\
\text {-Processing (more efficient) } \\
\text {-Systems (innovative/flexible) } \\
\text { Finding } \\
\text { o Poor website design } \\
\text { o Poor search }\end{array}$ & $\begin{array}{l}\text { Expected } \\
\text { - Attribute (entrepreneurial) } \\
\text { - Involvement (highly non-inclusive) } \\
\text { - Knowledge (expanded) } \\
\text { - Actions (transparent, and measurable) } \\
\text { - Discretion (expanded) } \\
\text { - Impact (highly limited) } \\
\text { Finding } \\
\text { O IT as overhead } \\
\text { O Poor understanding of the actual value of IT } \\
\text { (low use of IT) }\end{array}$ \\
\hline & $\begin{array}{l}\text { Public } \\
\text { Bureaucracy }\end{array}$ & $\begin{array}{l}\text { Existing } \\
\bullet \text { Nature (analogue) } \\
\text { •Medium (paper) } \\
\text { •Knowledge (sticky) } \\
\text { • Movement (low speed) } \\
\text { •Processing (less efficient) } \\
\text { •Systems (customary/routine) } \\
\\
\text { Finding } \\
\text { ○ Poor legacy systems } \\
\text { o Poor information sharing } \\
\text { ○ Managers making decisions } \\
\text { without adequate } \\
\text { information }\end{array}$ & $\begin{array}{l}\text { Existing } \\
\text { - Attribute (non-entrepreneurial) } \\
\text {-Involvement (moderately non-inclusive) } \\
\text { - Knowledge (limited) } \\
\text { - Activities (transparent and measurable) } \\
\text {-Discretion (limited) } \\
\text { - Impact (limited) } \\
\\
\text { Finding } \\
\text { o Ad hoc processes } \\
\text { o Poor collaboration between managers } \\
\text { o Poor organisation learning } \\
\text { o Low commitment levels to BV } \\
\text { o Managers make decisions by intuition } \\
\text { (without adequate information) }\end{array}$ \\
\hline & & Information & People \\
\hline & & \multicolumn{2}{|c|}{ INFORMATION MANAGEMENT ELEMENTS } \\
\hline
\end{tabular}

Fig. 1. Relationship between the institutions and information management elements

The employees' exhibition of low commitment to the Best Value Practices (BVP) can be explained by the non-inclusive terms by which they were involved in the organisation. The social foundations of the bureaucratic order are the non-inclusive involvement of employees in organisations [22]. Only the individual's role (not the full person) is included in formal organising. The effects of non-inclusivity are 
over-specialisation, limited discretion and low inclination to initiative-taking. Thus, Özcan and Reichstein [32, p.606] argue that a chief concern among public employees is their "diminished sense of impact." Commitment to BVP would entail employees' initiatives and contingent behaviours, but bureaucratic rules are purported to exclude them. It would also entail employees' efforts to be recognised and rewarded, but their sense of inability to make any changes holds them back.

\subsection{Relationship between Information Technology and People}

Information technology as an institution was envisioned to address all the problems that employees of public organisations face due to the effects of bureaucracy. IT integration in public organisations aims at their low-entrepreneurial ethos to induce high degrees of entrepreneurship. This has been the predominant philosophy of the new public management (NPM) reform agenda $[16,31]$ which proposes a radical change in the underlying logic of public organisations, and in the parameters of assessing actions therein. It assumes that public bureaucratic organisations that aim for effectiveness must be reformed to aim for efficiency [33]. At the time of this research, NPM had highly informed the BVP ideal. But, interestingly, the efficiency or market orientation of the Council's employees through IT did not materialise. This is because those efficiency ideals of IT were challenged considerably by lowentrepreneurial attitudes and expedient actions of the employees.

Thus, employees had poor understanding of the value of IT that caused management to perceive IT as overhead. The envisioned value of IT, informed by NPM-based Best Value Practices, was to make actions more transparent, measurable and efficient. The institution of IT is imbued with an efficiency order borne of the entrepreneurship in its production and consumption. IT production is now a predominant aspect of the global economy [2], as witnessed in the emergence of giant internet and software businesses and their high-valued technology stocks in the international exchange markets. IT consumption is also commonplace in organisations' innovation initiatives aimed at gaining competitive advantage. However, public organisations are not even judged by efficiency but by effectiveness in delivery of services equitably and impartially . Employees' poor understanding of the value of IT, thus, lied in their judgment that it was largely impotent for effectiveness in the public organisational context.

\subsection{Relationship between Public Bureaucracy and Information}

The low-entrepreneurial ethos of public bureaucracy reflects the nature, media, processing, and systems of information in it. The paper-based media that bear information in public organisations inherently inhibit information sharing. This is because reproduction and dissemination of information with these media are relatively expensive, and therefore prohibitive. Movement of information with these media is slow and cumbersome, inducing the generation of information silos and barriers. Beside the media, the information culture of employees can explain the poor information sharing. Alavi and colleagues [1], for example, argue that employees will share information if their organisation operates a group reward scheme; and vice versa. Individual reward schemes are prevalent in public organisations because of the 
high degrees of specialisation associated with employees. Skills specialisation coupled with on-the-job training increase the transaction and opportunity costs of leaving public organisations [32]. Employees are, therefore, induced to protect their roles by keeping information tacit instead of sharing to make them explicit. This results in the "stickiness" of knowledge [5] in particular specialisations at the expense of others.

\subsection{Relationship between Information Technology and People}

IT as an institution is believed to engender efficiency in information capturing, processing, storage, and dissemination. This belief rests on the digital nature of computer-based information which makes it very amenable for easy sharing, for informing citizens through its website, and for enhancing citizens' search for information on the website. Easy information sharing through IT would have resulted in the "leakiness" of knowledge [5] across specialisations in the Council. But the reality was "sticky" knowledge. The poor design of the Council's website and the poor search reflected poor use of internet technology to inform citizens about the various services being offered. Managing information on a website demanded constant updating of the pieces of information and tagging them with the relevant metadata according to established standards of Best Value Practices. These would depend on both responsiveness and initiatives of the employees. However, the dependence on employees' initiatives for providing timely and accurate information to citizens through a website seems to be a monumental challenge. This is because, rewards and promotions are not necessarily tied to employees' contributions in public organisations [32]. Therefore, it is difficult to suddenly turn to depend on employee initiatives for information sharing, and knowledge creation and synthesis. It is likely they will not be motivated to match the demands of IT with their responses.

\section{Discussion}

The institutional analysis of the challenges of IS innovation induces us to exercise greater circumspection when addressing them. Its central argument is that the primary step of IS innovation is to understand the unquestionable forces behind the orders of IT and public bureaucracy as well as their implications for information management. The primary step is not to think of structuring or restructuring bureaucratic or lowentrepreneurial processes of public organisations with IT, or vice versa. Rather, it is to think of confronting these institutions with the aim of adjusting and aligning them .

Institutional adjustment reflects the old maxim of IS that says 'if you do not sort out your mess before computerizing, you computerize the mess, and end up being worse off.' But this maxim is losing its appeal because of increasing claims in the IS literature that computerization can be used to sort out the mess in high-entrepreneurial organisations [e.g. 17]. Interestingly, IT and high-entrepreneurial organisations share the same efficiency principle and are easily substitutable. Therefore, the claims can be true in that context but may not be true in the context of public organisations. The principle of practice in public organisations is effectiveness in equitable distribution of services to citizens, making IT substitution an imprudent prospect. Therefore, IS 
innovation should be approached from aligning IT and public organisations according to their institutional realities, not according to the high expectations from substitution, transformation, structuration and reform.

This paper's argument resonates with the works of Cordella [8] and Dunleavy and colleagues [11] who reject the efficiency goals of the NPM agenda. Cordella calls for e-government projects to apply IT to public bureaucracy with the aim of achieving the e-bureaucratic form. The e-bureaucratic form appreciates the enduring role of public bureaucracy in delivering public services effectively, as this paper argues. However, his discussion of this form is limited because it takes IT for granted by refusing to problematise it. This paper, however, problematises both IT and public bureaucracy and provides a more holistic discussion of the relationship between them.

Dunleavy and colleagues' pronouncement of the death of NPM is supported by a critique of its many limitations $[11,12]$. Their critique is in harmony with that of this paper. But their proposal focuses on reintegration of various government organisations that were separated or privatised under NPM; on interactions between public organisations and clients in terms of the latters' needs; and on using digitisation as transformative rather than supplementary to organisational processes. Thus, digital-era governance privileges technological determinism and optimism in its tenets while this paper does not do so.

Fountain $[13,15]$ also approaches IT integration in public organisations from an institutional perspective. In harmony with this paper's argument, she concludes that egovernment efforts will not live up to their expectations if organizational and social institutions remain the same. Indeed, she argues, just as this paper, against substitution of social or organisational processes with technology [13, p.80]. However, her approach does not consider technology as an institution, but as an instrument, leaving her institutional change arguments limited to public bureaucracy. With an instrumental, rather than institutional, view of technology, her analysis of it is confined to interpretive flexibility at the organisational level. Moreover, her institutional approach fails to show how institutional obstacles can be overcome to lead to change. But this paper explains it primarily in terms of institutional change, and considers organisational analysis of technology as secondary.

\subsection{Suggestions for Adjusting Public Bureaucracy}

If any processes in public bureaucracy are perceived to be messy or problematic and need sorting out, then that should be done by adjusting the institution itself rather than depending on IT. One useful approach to institutional adjustment in public bureaucracy is to understand it in terms of constitutive and variable characteristics of the bureaucratic order [22]. The variable characteristics such as standardised and centralised operating procedures can be reassembled, recombined and reshuffled to deal with contingences that emerge. DiMaggio and Powell [10] provide useful insights on the sources of these variable characteristics and how they cause institutional homogeneity in public organisations. Institutional homogeneity refers to those characteristics shared by public organisations to make them so similar. By their insights, public organisations are typical instances of public bureaucracy shaped by external constraints imposed by the state, employee migrations, and the professions. Interestingly, these sources lie outside the influence of public organisations, making it 
difficult for the changes to be initiated from the organisational level. The external influences make it even more difficult to depend on the instrumental order of IT to change the variable characteristics of the bureaucratic order. Changes in these external sources should be the bases of institutional adjustment in public bureaucracy that will, hopefully, translate into changes in operating procedures and employee roles.

\subsection{Suggestions for Adjusting IT}

The institutional approach to IS innovation suggests a departure from visions of appropriation of IT by employees and structuration of their processes at the institutional level. It calls for restraining IT commitments and expectations in respect of the various IT projects ongoing or intended in public organisations. This is quite unusual because of the unquestioned momentum of the IT institution in e-government projects, yet it is a prudent choice for public organisations. It suggests a lowering of expectations from IT in terms of efficiency, rationality, and entrepreneurship, as in the NPM agenda. IT also suggests aiming IT projects not at automating all public organisational processes, but only the few that are already reasonably rationalised and efficient. This will substitute those processes with automated versions, thus confining the regulative regime of technology to them only [23]. IT can be programmed to include a very wide variety of functions that can provide options for various users in public organisations. Aiming for technology that has this capability underscores the institutional adjustment argument of this paper because the technology itself becomes the target of transformation. Institutional adjustment of IT aims at making technology amenable and constructible by public organisations instead of making it the determinant.

\section{Conclusion}

The aim of this paper was to analyse, from an institutional perspective, the labyrinths of IS innovation in public organisations. An important aspect of this perspective is the perception of IT as an institution in its own right. The analysis has revealed that if each of IT and public bureaucracy are adjusted properly at their institutional levels, then their alignment at the organisational level will be less problematic. At the organisational level, their interaction in operations will be more effective and useful for equity and impartiality in the delivery of public services. Taking the institutional approach to IS innovation in public organisations is, therefore, important for analysing the tensions between IT and public organisations.

\section{References}

1. Alavi, M., Kayworth, T., Leidner, D.E.: An Empirical Examination of the Influence of Organizational Culture on Knowledge Management Practices. Journal of Management Information Systems 22, 191-224 (2005)

2. Avgerou, C.: IT and Organizational Change: An Institutionalist Perspective. Information Technology and People 13, 234-262 (2000)

3. Avgerou, C.: Information Systems and Global Diversity. Oxford University Press, Oxford (2002) 
4. Bellamy, C., Taylor, J.A.: Governing in the Information Age. Open University Press, Buckingham (1998)

5. Brown, J.S., Duguid, P.: Organizing Knowledge. California Management Review 40, 90-111 (1998)

6. Chadwick, A., May, C.: Interaction between States and Citizens in the Age of the Internet: E-Government in the United States, Britain and the European Union. Governance: An International Journal of Policy, Administration and Institutions 16, 271-300 (2003)

7. Chisholm, R.F.: Introducing Advanced Information Technology into Public Organizations. Public Productivity Review 11, 39-56 (1988)

8. Cordella, A.: E-Government: Towards the E-Bureaucratic Form? Journal of Information Technology 22, 265-274 (2007)

9. Daft, R.L.: A Dual-Core Model of Organizational Innovation. Academy of Management Journal 21, 193-210 (1978)

10. DiMaggio, P.J., Powell, W.W.: The Iron Cage Revisited: Institutional Isomorphism and Collective Rationality in Organizational Fields. American Sociological Review 48, 147-160 (1983)

11. Dunleavy, P., Margetts, H., Bastow, S., Tinkler, J.: New Public Management is Dead Long Live Digital-Era Governance. Journal of Public Administration Research and Theory 16, 467-494 (2005)

12. Dunleavy, P., Margetts, H., Bastow, S., Tinkler, J.: Digital Era Governance: IT Corporations, the State, and e-Government. Oxford University Press, Oxford (2006)

13. Fountain, J.E.: Building the Virtual State: Information Technology and Institutional Change. Brookings Institution Press, Washington (2001)

14. Fountain, J.E.: Information, Institutions, and Governance: Advancing a Basic Social Science Research Program for Digital Government. Kennedy School of Government, Harvard University (2003)

15. Fountain, J.E.: Bureaucratic Reform and E-Government in the United States: An Institutional Perspective 2007, National Centre for Digital Government (2007)

16. Gruening, G.: Origin and Theoretical Basis of New Public Management. International Public Management Journal 4, 1-25 (2001)

17. Gurbaxani, V., Whang, S.: The Impact of Informatuon Systems on Organizations and Markets. Communications of the ACM 34, 59-73 (1991)

18. Heeks, R.: Reinventing Government in the Information Age. In: Heeks, R. (ed.) Reinventing Government in the Information Age: International Practice in IT-enabled Public Sector Reform. Routledge, London (2001)

19. Henriksen, H.Z., Damsgaard, J.: Dawn of E-Government - An Institutional Analysis fo Seven Initiatives and their Impact. Journal of Information Technology 22, 13-23 (2007)

20. Irani, Z., Elliman, T., Jackson, P.: Electronic Transformation of Government in the UK: A Research Agenda. European Journal of Information Systems 16, 327-335 (2007)

21. Jepperson, R.L.: Institutions, Institutional Effects, and Institutionalism. In: Powell, W.W., DiMaggio, P.J. (eds.) The New Institutionalism in Organizational Analysis. University of Chicago Press, Chicago (1991)

22. Kallinikos, J.: The Social Foundations of the Bureaucratic Order. Organization 11, 13-36 (2004)

23. Kallinikos, J.: The Regulative Regime of Technology. In: Contini, F., Lanzara, G.F. (eds.) ICT and Innovation in the Public Sector: European Studies in the Making of E-government. Palgrave Macmillan, Basingstoke (2009)

24. Kim, S., Kim, H.J., Lee, H.: An Institutional Analysis of an E-Government System for Anti-Corruption. Government Information Quarterly 26, 42-50 (2009) 
25. Kraemer, K.L., King, J.L.: Information Technology and Administrative Reform: Will E-Government Be Different? International Journal of Electronic Government Research 2, 1-20 (2006)

26. Lanzara, G.F.: Building Digital Institutions: ICT and the Rise of Assemblages in Government. In: Contini, F., Lanzara, G.F. (eds.) ICT and Innovation in the Public Sector: European Studies in the Making of E-Government. Palgrave Macmillan, Basingstoke (2009)

27. Meyer, J.W., Rowan, B.: Institutionalized Organizations: Formal Structure as Myth and Ceremony. American Journal of Sociology 83, 340-363 (1977)

28. Moe, T.M.: The Politics of Structural Choice: Toward a Theory of Public Bureaucracy. In: Williamson, O.E. (ed.) Organization Theory: From Chester Barnard to the Present and Beyond. Oxford University Press, New York (1990)

29. O'Donnell, O., Boyle, R., Timonen, V.: Transformational Aspects of E-Government in Ireland. Electronic Journal of Electronic Government 1, 23-32 (2003)

30. Oliver, C.: Strategic Responses to Institutional Processes. Academy of Management Review 16, 145-179 (1991)

31. Osborne, D., Gaebler, T.: Reinventing Government: How the Entrepreneurial Spirit is Transforming the Public Sector. Addison-Wesley, Reading (1992)

32. Özcan, S., Reichstein, T.: Transition to Entrepreneurship from the Public Sector: Predispositional and Contextual Effects. Management Science 55, 604-618 (2009)

33. Pollit, C., Bouchaert, G.: Public Management Reform. Oxford University Press, Oxford (2004)

34. Swanson, E.B.: Information Systems Innovation Among Organizations. Management Science 40, 1069-1092 (1994)

35. Yin, R.K.: Case Study Research: Design and Methods. Sage, Newbury Park (1984) 